\title{
Korean Version of the Voice Activity and Participation Profile (K-VAPP): A Validation Study
}

\author{
Seung Jin Lee ${ }^{\mathrm{a}, \mathrm{b}}$, Hong-Shik Choi ${ }^{\mathrm{b}, \mathrm{c}}$, HyangHee Kim ${ }^{\mathrm{a}, \mathrm{d}}$, Hyung Kwon Byeon ${ }^{\mathrm{b}, \mathrm{c}}$, Sung-Eun Lim ${ }^{\mathrm{e}}$, Min Kyo Yang ${ }^{\mathrm{b}, \mathrm{f}}$ \\ ${ }^{a}$ Graduate Program in Speech Language Pathology, Yonsei Uniersity, Seoul, Korea \\ ${ }^{b}$ The Institute of Logopedics and Phoniatrics, Department of Otorhinolaryngology, Gangnam Severance Hospital, Seoul, Korea \\ 'Department of Otorhinolaryngology, Yonsei University College of Medicine, Seoul, Korea \\ ${ }^{d}$ Department and Research Institute of Rehabilitation Medicine, Yonsei University College of Medicine, Seoul, Korea \\ ${ }^{e}$ Voice Clinic, Department of Otorhinolaryngology, Gangnam Severance Hospital, Seoul, Korea \\ Interdisciplinary Program of Psychology Rehabilitation, Myongji University, Seoul, Korea
}

Correspondence: Seung Jin Lee, MA

Graduate Program in Speech and Language

Pathology, Yonsei University, 50-1 Yonsei-ro,

Seodaemun-gu, Seoul 03722, Korea

Tel: $+82-2-2228-3900$

Fax: +82-2-2227-7984

E-mail: slplee80@gmail.com

Received: October 5, 2016

Revised: November 24, 2016

Accepted: December 2, 2016

This work was presented in part at the Conference of the Korean Academy of Speech-Language Pathology and Audiology 2016, Seoul, Korea, and awarded Best Paper Award.
Objectives: The purpose of this study was to confirm the validity and reliability of the Korean version of the Voice Activity and Participation Profile (K-VAPP), which is a self-reported questionnaire to measure activity limitation and participation restriction caused by voice disorders. Methods: The original version of the VAPP was translated into Korean to achieve conceptual and linguistic equivalence and to evaluate measurement properties. The KVAPP was administered to 300 participants (150 with vocal complaints, 150 without vocal complaints). The instrument was evaluated with regards to its validity, reliability and cutoff scores for the total score, activity limitation score (ALS), and participation restriction score (PRS). Results: The total score, ALS, PRS, and five subscale scores of the patient group were higher than those of the control group. Concurrent validity, internal consistency, test-retest reliability, and item discrimination were satisfactory. The cutoff scores of the total score, ALS, and PRS were 14.5, 4.5, and 1.5, respectively. The clinical implications of these findings are discussed. Conclusion: The K-VAPP was proven to have sufficient validity and reliability to be used in Korean voice clinics and research. Further studies related to its responsiveness and various profiles with different etiologies or profession groups are needed.

Keywords: Voice Activity and Participation Profile, Validation, K-VAPP, ICF, Psychometric assessment, Voice disorder
음성장애는 “음성의 질, 음도, 크기, 변이성이 유사한 연령, 성별, 문화 집단과 다른 것”을 말하며(Aronson \& Bless, 2009), 단순히 후 두에서 관찰되는 비정상적인 형태학적 소견이나 귀에 들리는 비정 상적인 음성의 질 이상의 것이므로, 환자의 삶에 미치는 영향이 함 께 고려되어야 한다(Ma \& Yiu, 2011). 따라서, 임상현장에서는 종 합적이고 다차원적인 평가를 위하여 음향학, 청지각 평가와 함께 환자의 자기보고에 의한 심리측정적(psychometric) 평가가 널리 이 용된다. 그 이유는 임상가와 환자가 인식하는 음성장애의 정도 차 이에 대한 정보를 얻을 수 있기 때문이다(Ma \& Yiu, 2001). 이는 중 재 프로그램 계획에 중요하며, 중재의 성과를 측정하는 가늠자가 되기도 한다(Zraick et al., 2007).
자기보고식 심리측정적 평가도구로 음성장애지수(Voice Handicap Index, VHI)가 있으며, 두 버전의 한국어판(Kim et al., 2007; Yun, Kim, Son, \& Choi, 2008)으로 번안되어 우리나라 음성클리닉 임상 현장에서 널리 이용되고 있다. 그러나, VHI는 음성장애로 인하여 일 상 활동에서 받는 제한(activity limitation)과 해당 활동에 실제 참여 하는 것에 대한 제약(participation restriction)을 분리하여 평가할 수 없다(Aronson \& Bless, 2009; Ma \& Yiu, 2001). 한국어판 음성관 련 삶의 질(Korean version of Voice-Related Quality of Life, KVQOL; Kim et al., 2007) 또한 유사한 한계가 있다. 양자를 분리하여 평가해 야 하는 이유는, 활동 제한과 참여 제약 간 격차가 최적의 중재 전략 을 설정하는 데 중요한 정보이기 때문이다(Threats, 2008). 
이를 극복하기 위해 국제기능건강분류(International Classification of Functioning, Disabilities, and Health)를 기반으로 음성 활 동 및 참여 프로파일(Voice Activity and Participation Profile, VAPP) 이 개발되었다(Ma \& Yiu, 2001). VAPP는 자기보고식 설문검사로 활동 제한과 참여 제약을 서로 분리하여 측정할 수 있으며(Resnik \& Plow, 2009), VHI에 비해 직업에 관한 문항을 더 많이 포함하고 있다. 애초 시각적 상사척도(visual analogue scale) 방식이었으나, 편의성 제고를 위해 11점 등간척도(equal-appearing interval scale) 방식(0점-10점)으로 개선되었다(Ma \& Yiu, 2007; Pires, Oliveira, \& Behlau, 2011). 총 28개 문항 280점 만점이며, 하위영역은 I. 목소리 문제의 심각한 정도에 대한 본인의 인식(1번 1개 문항), II. 직업에 대 한 영향(2-5번 4개 문항), III. 일상 의사소통에 대한 영향(6-17번 12 개 문항), IV. 사회적 의사소통에 대한 영향(18-21번 4개 문항), V. 본 인의 감정에 대한 영향(22-28번 7개 문항)이다. 하위영역 II, III, IV 의 문항(2-21번) 중 10 개(짝수)는 음성 활동의 제한 정도를 묻는 문 항(예: 본인의 목소리 문제 때문에 다른 사람들이 방금 한 말을 다 시 말해달라고 합니까?)이며, 해당 음성 활동에 대한 참여 제약 정 도를 묻는 10 개(홀수)(예: 지난 6 개월 동안, 본인의 목소리 문제 때 문에 다른 사람과 말하는 것을 피한 적이 있습니까)와 쌍을 이루어 활동 제한 점수(activity limitation score, ALS; 100점 만점)와 참여 제약 점수(participation restriction score, PRS; 100점 만점)가 각각 산출된다.

현재 VAPP는 이탈리아어(Fava, Paolillo, Oliveira, \& Behlau, 2015), 핀란드어(Kleemola, Helminen, Rorarius, Isotalo, \& Sihvo, 2011a), 포르투갈어(Ricarte, Oliveira, \& Behlau, 2013) 등 다양한 언어로 번안 및 표준화되어 임상과 연구에서 널리 사용되고 있다. 우리나 라 임상 현장에서는 $\mathrm{VHI}$ 와 $\mathrm{KVQOL}$ 을 제외하면 심리측정적 평가 도구가 부족하며, 활동 및 참여에 대한 측면까지 고려한 검사도구 는 전무한 실정이므로, $\mathrm{VAPP}$ 의 한국판 번안 및 표준화 연구는 임 상적 의의가 있다고 하겠다.

이에, 본 연구에서는 ‘음성 활동 및 참여 프로파일-한국판(Korean version of Voice Activity \& Participation Profile, K-VAPP)'을 적 절한 절차에 의거하여 번안하고, 이 번안본을 환자 및 정상인에게 적용하여 신뢰도와 타당도를 갖춘 도구인지 검증하며, 음성장애 환자 및 정상인의 규준을 제시함으로써 표준화하고자 하였다.

\section{연구 방법}

\section{연구 대상}

이 연구는 서울 소재 한 대학병원 윤리심의위원회(IRB)의 허가
를 받았다(IRB No. 3-2016-0073). G*Power (Faul, Erdfelder, Buchner, \& Lang, 2009)를 이용하여 두 집단의 중위수 비교(맨휘트니 검 정)를 위해 충분한 표본수를 산정한 결과, 각 집단별 110 명이었다 (effect size $=.5$, Power $=.95)$. 여기에 탈락률 $10 \%$ 를 고려하고, VAPP 의 이탈리아어 번안 연구(음성장애 환자군 131 명, 대조군 107 명), 핀란드어 번안 연구(환자군 142 명, 대조군 128 명), 그리고 $\mathrm{KVHI}$ (Korean version of Voice Handicap Index; Kim et al., 2007)(환자 군 156 명, 대조군 66 명)와 $\mathrm{KVQOL}$ (환자군 131명, 대조군 111명) 번 안 연구 등의 선행연구를 참고하여 음성장애 환자군 150 명(연령 $45.15 \pm 15.15$ 세), 대조군 150 명(연령 $42.31 \pm 11.86$ 세)으로 산정하 였다(Table 1).

환자군으로는 2016년 3월 11일부터 9월 28일까지 해당 병원 이비 인후과에 내원하여 음성정밀검사를 실시한 결과, 이비인후과 전문 의에 의해 기능적, 기질적, 신경학적 원인을 포함하는 다양한 음성 장애로 진단된 만 19 세 이상의 환자 150 명(남 42 명, 여 108명)을 대 상으로 하였다. 이때, 검사 전 음성장애에 대한 수술적, 행동적 치료 를 받지 않은 자로 한정하였다. 환자의 진단명은 성대 마비 29명, 인 후두 역류질환 23 명, 성대 폴립 21명, 성대 결절 19명, 내전형 연축성 발성장애 19명, 성대 낭종 9명, 기능적 발성장애 7명, 급성 후두염 5 명, 성대구증 5명, 근긴장성 발성장애 3 명, 성대 과각화증 3 명, 유두 종 2 명, 그리고 육아종, 혈관종, 성대 흥터, 구개인두 간대성 근경련 증(palatopharyngeal myoclonus), 혼합형 마비말장애 각 1 명이었다. 대조군은 만 19 세 이상의 서울 및 경기 지역에 거주 중인 한국어 모국어 화자로 흡연력이나 음성과 관련될 수 있는 신경학적 또는 질병관련 이슈가 보고되지 않았으며, 검사 시점 기준 3 개월 간 음성 문제를 주소로 이비인후과를 방문한 경험이 없는 자 150 명(남 42 명, 여 108명)이었다. 이때, '가을' 문단(Kim, 2012) 읽기 시의 음성 을 2 인의 1 급 언어재활사(이비인후과 음성클리닉에서 음성 평가 및 치료 경력 각 2년 6개월과 19년)가 GRBAS scale (Hirano, 1981)로 평정하여 합의를 도출한 결과 $\mathrm{G}$ (grade) 평정치가 0 인 자로 한정하

Table 1. Descriptive data of the participants

\begin{tabular}{lcc}
\hline & Patient group (N=150) & Control group (N=150) \\
\hline Age $(\mathrm{yr})$ & $45.15 \pm 15.15(19-86)$ & $42.31 \pm 11.86(20-71)$ \\
& $43.50(34.00-57.25)$ & $43.50(33.00-51.00)$ \\
Gender & & \\
Male & $42(28.0)$ & $42(28.0)$ \\
Female & $108(72.0)$ & $108(72.0)$ \\
Profession & & \\
Professional & $70(46.7)$ & $57(38.0)$ \\
Non-professional & $80(53.3)$ & $93(62.0)$ \\
\hline
\end{tabular}

Values are presented as mean \pm SD or median (interquartile range) or number (\%). 
였다. 문맹 또는 무학인 것으로 보고되거나, 문단 읽기 시 관찰 결과 읽기 문제가 있는 것으로 판단되는 대상자는 제외하였다. 맨휘트니 검정을 통해 살펴본 결과 환자군과 대조군 간 연령 차이는 없었고 ( $p=.375)$, 카이제곱 검정을 통해 살펴본 결과, $\operatorname{Kim}(2015)$ 의 기준 을 따른 직업적 음성 사용자의 비율 차이 또한 없었다 $(p=.129)$.

\section{번안 절차}

정확하고 적절한 번안을 위하여, 심리측정적 특성을 수량화하 는 검사를 번안하는 데 권고되는 기준들(Aaronson et al., 2002)을 준수하여 번안 절차를 진행하였다. 먼저, 원저자인 Dr. Estella Ma (Associate Professor, Division of Speech and Hearing Sciences, University of Hong Kong)와의 교신을 통하여 공식 허가를 득한 후, 연구진 중 1 인을 포함한 2 인의 1 급 언어재활사가 원본 설문지를 한국어로 순번역하였다. 이때, 문자 그대로 하기보다는 개념적 번역 을 하였다. 두 번안본 간 불일치에 대해 합의에 이를 때까지 논의하 여 하나의 번안본이 확정되었으며, 대상자의 이해를 돕기 위한 지시 사항을 검사지 앞 부분에 추가하였다. 그 뒤 이비인후과에서 음성 검사 및 치료를 주요 업무로 한 경력이 5 년 이상인 4 인의 1 급 언어재 활사들이 이 번안본을 검증하였다. 이때, 의미론('직장일, 자존감, 자아상' 등의 특정 어휘들), 통사론적 측면('본인’ 등 주어의 반복적 사용, 부사구, 어순, 수동/능동태), 지시사항의 적절성 측면에서 수 정 및 부연설명(예: ‘자아상'에 대하여 '자신에 대한 이미지나 생각') 제안이 이루어졌다. 이를 토대로 한 수정본에 대해 다수의 말-언어 검사도구 번안 및 표준화 경력이 있는 언어병리학 전공학과 교수 1 인을 포함한 2 인의 연구진의 검증을 거쳐 내용이 확정되었다.

이를 번안 절차에 참여하지 않은 1 인의 이중언어(영어와 한국어) 사용자가 역번역한 후, 위의 연구진 2 인이 원본과 비교하여 불일치 에 대한 토론과 수정을 거쳐 최종본을 확정하였으며, 정상인 3인과 음성장애 환자 1 인에게 예비 시행하여 부적절한 항목이 없음을 확 인하였다. 다만, 대상자의 의견을 토대로 11 점 등간척도의 시안성을 개선하고, 활동과 참여 항목 간 용이한 구분을 위해 '실제로 피한 적이 있는지를 답하시면 됩니다'라는 문구를 참여 항목에 추가하 였다. 채점을 용이하게 하기 위해 활동 제한 항목의 앞에는 'A'를, 참 여 제약 항목의 번호 앞에는 'P'를 표기하였다(Appendix 1).

\section{검사절차}

먼저 사전 면담을 통하여 직업, 발병일, 음성장애 치료력 등의 정 보를 수집하였다. 대조군의 경우 설문 전 '가을' 문단(Kim, 2012) 읽 기를 시행하여 잠재적 읽기/시각 문제나 음성 문제를 가진 대상자 를 선별하였다. 공인타당도 구축을 위하여 KVHI와 K-VAPP를 실
시하되, 순서에 의한 편견(bias)을 배제하기 위하여 대상자 중 $50 \%$ 는 KVHI를, 나머지 50\%는 K-VAPP를 먼저 시행하였다.

\section{타당도 및 신뢰도 검증}

내용타당도 검증을 위해서는 전술한 바와 같이 전문가 집단의 검증과 예비검사를 거쳤다. 구성타당도 검증을 위해 Mann-Whitney $U$-test를 이용하여 집단 간 점수 비교를 하였고, 공인타당도 검 증을 위해 KVHI 총점 및 하위영역 점수들과의 Spearman 상관분 석을 통해 상관관계를 살펴보았다. 내적 일치도 검증을 위해 환자 군 및 대조군 각각에 대하여 Cronbach's alpha coefficient를 산출 하였고, 검사-재검사 신뢰도 검증을 위해 전체의 $10 \%$ 에 해당하는 30 명의 대상자에게 초회 검사 후 2-14일 이내에 재검사를 실시하여 총점, ALS, PRS 및 각 하위영역에 대하여 급내상관계수(intra-class correlation coefficient, ICC)를 산출하였다(일차원 변량). 문항변 별도 검증을 위해 환자군의 문항별 결과에 대하여 수정된 문항-총 점 상관관계 분석을 실시하였다. Receiver operating characteristic (ROC) curve analysis를 이용하여 K-VAPP의 총점, ALS, PRS에 대 해 각 점수별 민감도와 특이도를 산정한 후 엑셀시트를 이용하여 가장 높은 민감도와 특이도를 보이는 절단점을 확인하였다. 모든 통계 분석에는 SPSS version 23.0 software (IBM-SPSS Inc., Armonk, $\mathrm{NY}, \mathrm{USA})$ 를 이용하였다.

\section{연구 결과}

\section{타당도}

집단별로 총점, $\mathrm{ALS}, \mathrm{PRS}$, 하위영역별 점수의 정규성 검정을 위 한 Shapiro-Wilk test를 시행한 결과, 모든 점수가 정규분포를 이루 지 않았다 $(p<.001)$. 이에 집단 간 점수 차이를 Mann-Whitney $U$ test를 통해 비교한 결과, 환자군의 점수들이 모두 유의하게 높았다 $(p<.001)$ (Table 2). K-VAPP와 KVHI 점수 간 상관관계를 살펴 본 결과, 두 검사 간 유의한 양의 상관관계가 있었으며 $(p<.001)$, Spearman's rho의 범위는 .483-.840였다(Table 3).

\section{신뢰도}

Cronbach's alpha는 환자군에서 .974, 대조군에서 .911이었다. 총 점, ALS, PRS의 검사-재검사 간 ICC는 각각 .962, .926, .936이었으 며, 하위영역별 ICC는 각각 $.803, .947, .852, .892, .957$ 였다. 환자군 에 대해 문항별 문항-총점 상관관계를 살펴 본 결과, 문항변별도의 범위는 .565-845이었다(Table 4). 문항 제거 시 Cronbach's alpha가 현저히 증가한 항목은 없었다. 


\section{절단점}

ROC curve analysis를 시행한 결과, K-VAPP 총점, ALS, PRS, $\mathrm{KVHI}$ 총점의 곡선아래영역(AUC)은 각각 $.957, .927, .930, .917$ 이었 다(Figure 1). 가장 높은 민감도와 특이도를 가진 K-VAPP 총점, ALS, PRS의 절단점은 각각 14.5 점, 4.5 점, 1.5 점이었다(Table 5).

\section{논의 및 결론}

음성장애에 대한 심리측정적 평가는 환자에게 적합한 중재 전략

Table 2. Results of the K-VAPP and KVHI scores for each group

\begin{tabular}{lcccc}
\hline Subsection & $\begin{array}{c}\text { Maximum } \\
\text { score }\end{array}$ & $\begin{array}{c}\text { Patient } \\
\text { group }\end{array}$ & $\begin{array}{c}\text { Control } \\
\text { group }\end{array}$ & $p$-value \\
\hline K-VAPP $_{\text {TL }}$ & 280 & $114.74 \pm 77.68$ & $4.20 \pm 8.61$ & $<.001$ \\
ALS & 100 & $37.59 \pm 28.01$ & $1.79 \pm 3.36$ & $<.001$ \\
PRS & 100 & $36.98 \pm 29.32$ & $.90 \pm 2.65$ & $<.001$ \\
SUB1 & 10 & $5.92 \pm 3.06$ & $.39 \pm .91$ & $<.001$ \\
SUB2 & 40 & $15.65 \pm 13.28$ & $.46 \pm 1.62$ & $<.001$ \\
SUB3 & 120 & $46.15 \pm 36.38$ & $1.89 \pm 4.08$ & $<.001$ \\
SUB4 & 40 & $12.77 \pm 11.88$ & $.33 \pm 1.03$ & $<.001$ \\
SUB5 & 70 & $34.25 \pm 23.68$ & $1.13 \pm 3.72$ & $<.001$ \\
Job & ALS (20) & $9.55 \pm 7.36$ & $.31 \pm .96$ & $<.001$ \\
& PRS (20) & $6.11 \pm 6.82$ & $.15 \pm .80$ & $<.001$ \\
Daily communication & ALS (60) & $21.82 \pm 18.56$ & $1.30 \pm 2.69$ & $<.001$ \\
& PRS (60) & $24.33 \pm 19.25$ & $.59 \pm 1.76$ & $<.001$ \\
Social communication & ALS (20) & $6.22 \pm 5.85$ & $.18 \pm 0.53$ & $<.001$ \\
& PRS (20) & $6.55 \pm 6.62$ & $.15 \pm 0.63$ & $<.001$ \\
KVHI $I_{\text {TL }}$ & 120 & $47.97 \pm 29.69$ & $6.51 \pm 8.45$ & $<.001$ \\
KVHIF & 40 & $13.99 \pm 10.89$ & $1.97 \pm 2.94$ & $<.001$ \\
KVHIP & 40 & $20.03 \pm 9.67$ & $3.35 \pm 4.16$ & $<.001$ \\
KVHIE & 40 & $13.95 \pm 11.40$ & $1.18 \pm 2.64$ & $<.001$ \\
\hline
\end{tabular}

Values are presented as mean $\pm S D$.

$\mathrm{K}-\mathrm{VAPP}=$ Korean version of the Voice Activity and Participation Profile; $\mathrm{K}-\mathrm{VAPP}_{\pi \mathrm{L}}=$ total score of the K-VAPP; SUB1 = score of the subsection I; SUB2 = score of the subsection II; SUB3 = score of the subsection III; SUB4 = score of the subsection IV; SUB5 = score of the subsection $\mathrm{V} ; \mathrm{KVHI}=$ Korean-version of Voice Handicap Index; $\mathrm{KVH} \mathrm{I}_{\mathrm{TL}}$ $=$ total score of the $\mathrm{KVHl} ; \mathrm{KVH} \|_{\mathrm{F}}=$ functional subscale score of the $\mathrm{KVH} ; \mathrm{KVH} \|_{\mathrm{p}}=$ physical subscale score of the $\mathrm{KVHI} ; \mathrm{KVHI}_{\mathrm{E}}=$ emotional subscale score of the $\mathrm{KVHI}$.
을 결정하거나, 중재의 성과를 측정하는 데 중요하다. 본 연구에서 살펴 본 바로는 K-VAPP는 이러한 목적에 충분한 수준의 신뢰도와 타당도를 지닌 검사도구로서 음성장애의 임상 또는 연구에 활용될 수 있을 것으로 여겨진다.

타당도 측면에서 환자군의 점수들이 모두 유의하게 높았던 것은

Table 4. Corrected item-total correlation analysis for each item of the K-VAPP

\begin{tabular}{|c|c|c|}
\hline Item & $\begin{array}{l}\text { Corrected item-total } \\
\text { correlation coefficient }\end{array}$ & $\begin{array}{c}\text { Cronbach's a if item } \\
\text { deleted }\end{array}$ \\
\hline 1 & .726 & .973 \\
\hline 2 & .671 & .973 \\
\hline 3 & .565 & .974 \\
\hline 4 & .682 & .973 \\
\hline 5 & .584 & .974 \\
\hline 6 & .767 & .973 \\
\hline 7 & .845 & .972 \\
\hline 8 & .772 & .972 \\
\hline 9 & .764 & .972 \\
\hline 10 & .701 & .973 \\
\hline 11 & .665 & .973 \\
\hline 12 & .788 & .972 \\
\hline 13 & .743 & .973 \\
\hline 14 & .804 & .972 \\
\hline 15 & .815 & .972 \\
\hline 16 & .808 & .972 \\
\hline 17 & .808 & .972 \\
\hline 18 & .805 & .972 \\
\hline 19 & .770 & .972 \\
\hline 20 & .747 & .973 \\
\hline 21 & .730 & .973 \\
\hline 22 & .790 & .972 \\
\hline 23 & .729 & .973 \\
\hline 24 & .724 & .973 \\
\hline 25 & .784 & .972 \\
\hline 26 & .773 & .972 \\
\hline 27 & .792 & .972 \\
\hline 28 & .724 & .973 \\
\hline
\end{tabular}

$\mathrm{K}-\mathrm{VAPP}=$ Korean version of the Voice Activity and Participation Profile.

Table 3. Correlation matrix between K-VAPP and KVHI

\begin{tabular}{lcccccccc}
\hline & K-VAPP & ALS & PRS & SUB1 & SUB2 & SUB3 & SUB4 & SUB5 \\
\hline KVH $\|_{T L}$ & $.804^{* * *}$ & $.840^{* * *}$ & $.695^{* * *}$ & $.649^{* * *}$ & $.537^{* * *}$ & $.792^{* * *}$ & $.698^{* * *}$ & $.715^{* * *}$ \\
KVH $\left.\right|_{F}$ & $.754^{* * *}$ & $.812^{* * *}$ & $.686^{* * *}$ & $.589^{* * *}$ & $.500^{* * *}$ & $.779^{* * *}$ & $.683^{* * *}$ & $.601^{* * *}$ \\
$K V H H_{P}$ & $.701^{* * *}$ & $.732^{* * *}$ & $.602^{* * *}$ & $.623^{* * *}$ & $.483^{* * *}$ & $.687^{* * *}$ & $.588^{* * *}$ & $.631^{* * *}$ \\
KVH & $.776^{* * *}$ & $.782^{* * *}$ & $.654^{* * *}$ & $.604^{* * *}$ & $.516^{* * *}$ & $.734^{* * *}$ & $.676^{* * *}$ & $.750^{* * *}$ \\
\hline
\end{tabular}

K-VAPP = Korean version of the Voice Activity and Participation Profile; K-VAPP $m$ = total score of the K-VAPP; SUB1 = score of the subsection l; SUB2=score of the subsection II; SUB3 = score of the subsection III; SUB4= score of the subsection IV; SUB5= score of the subsection V; KVHI=Korean-version of Voice Handicap Index; KVHI $\pi$ = total score of the $\mathrm{KVHI} ; \mathrm{KVH}_{\mathrm{F}}=$ functional subscale score of the $\mathrm{KVH} ;$; $\left.\mathrm{KVH}\right|_{\mathrm{P}}=$ physical subscale score of the $\mathrm{KVHl} ; \mathrm{KVH}_{\mathrm{E}}=$ emotional subscale score of the $\mathrm{KVHI}$.

${ }^{* * *} p<.001$ (Spearman's rho). 


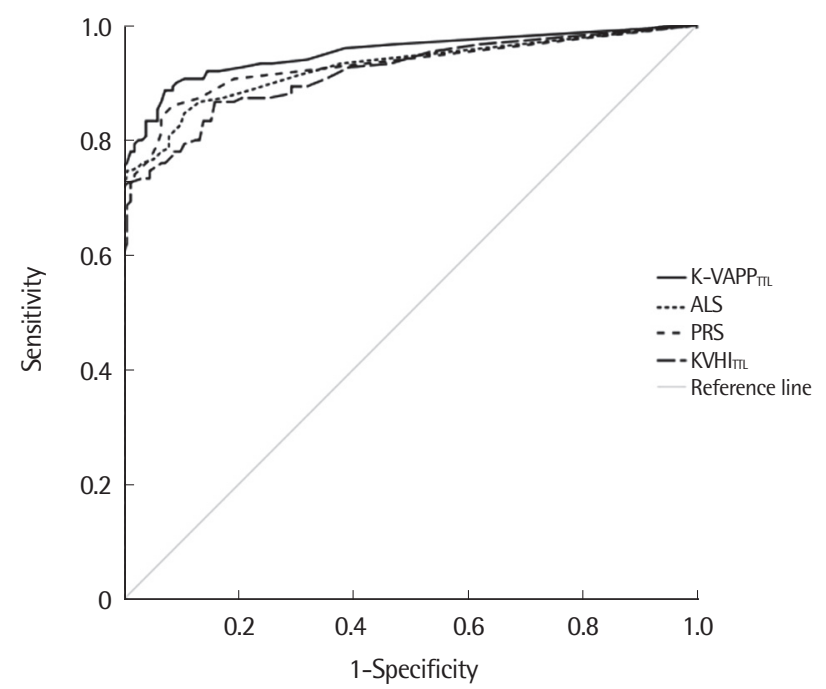

Figure 1. Receiver operating characteristic curve of the Korean version of the Voice Activity and Participation Profile (K-VAPP) total score, activity limitation score (ALS), and participation restriction score (PRS). KVHI=the Korean-version of Voice Handicap Index; K-VAPP $\pi \mathrm{T}=$ Total score of the Korean version of the Voice Activity and Participation Profile.

선행연구들과 일치하는 결과이다(Fava et al., 2015; Kleemola et al., 2011a; Ricarte et al., 2013). K-VAPP와 KVHI 점수 간 Spearman's rho의 범위(.483-.840) 또한 선행연구 결과(예: 이탈리아어판 .605.822, 핀란드어판 .314-855)를 고려할 때에도 충분한 수준이었다. 직업 하위영역은 $\mathrm{KVHI}$ 와 상관성이 낮은 편이었는데, 이는 $\mathrm{KVHI}$ 에 직업 관련 항목이 단 한 가지이기 때문인 것으로 풀이된다(‘내 목소리로 인해 내 수입에 영향을 받는다').

신뢰도 측면에서 Cronbach's alpha가 각 집단에서. 8 이상으로 충 분한 수준이었다. 문항 제거 시 alpha 값을 상승시키는 문항이 없었 으므로, 전체 신뢰도에 부정적인 영향을 주는 문항이 없었던 것으 로 해석되며, 문항변별도는 모든 문항에서 4 이상으로 충분하였다. 총점, $\mathrm{ALS}, \mathrm{PRS}$, 각 하위영역의 검사-재검사 신뢰도 또한 양호한 수 준이었으므로, K-VAPP의 신뢰도 및 타당도가 전반적으로 충분하 였다고 사료된다. 다만, 내적 일치도가 매우 높은 것은 역설적으로 잉여적인 항목의 존재 가능성을 시사하므로(Deary, Wilson, Carding, \& MacKenzie, 2003; Fava et al., 2015), 축약판에 대한 후속 연 구를 통하여 임상적 유용성을 제고할 수 있을 것으로 여겨진다.

$\mathrm{K}-\mathrm{VAPP}$ 총점, $\mathrm{ALS}, \mathrm{PRS}, \mathrm{KVHI}$ 총점의 곡선아래영역(AUC)은 모두 .9 이상으로 충분하였으나, 총점 절단점(14.5점)은 이탈리아어 판 연구(37.45점)에 비해 낮은 편이었다. 이는 본 연구에서 대조군 선정 시 청지각 평가를 통해 비정상 음성 소유자를 배제함으로써, 자기보고에만 의존하였던 선행연구에 비해 기준이 더 엄격했기 때 문인 것으로 보인다(Fava et al., 2015).
Table 5. Coordinates of the ROC curve for the cutoff point of the K-VAPP total score, ALS, and PRS

\begin{tabular}{rrrrrrrrr}
\hline $\begin{array}{r}\text { Total } \\
\text { score }\end{array}$ & $\begin{array}{c}\text { Sensi- } \\
\text { tivity } \\
(\%)\end{array}$ & $\begin{array}{c}\text { Speci- } \\
\text { ficity } \\
(\%)\end{array}$ & ALS & $\begin{array}{c}\text { Sensi- } \\
\text { tivity } \\
(\%)\end{array}$ & $\begin{array}{c}\text { Speci- } \\
\text { ficity } \\
(\%)\end{array}$ & PRS & $\begin{array}{c}\text { Sensi- } \\
\text { tivity } \\
(\%)\end{array}$ & $\begin{array}{c}\text { Speci- } \\
\text { ficity } \\
(\%)\end{array}$ \\
\hline-1.0 & 1.000 & .000 & -1.0 & 1.000 & .000 & -1.0 & 1.000 & .000 \\
0.5 & .967 & .527 & -1.0 & 1.000 & .000 & -1.0 & 1.000 & .000 \\
1.5 & .960 & .613 & 0.5 & .933 & .620 & 0.5 & .907 & .807 \\
2.5 & .940 & .680 & 1.5 & .913 & .693 & 1.5 & .873 & .867 \\
3.5 & .933 & .740 & 2.5 & .887 & .780 & 2.5 & .860 & .913 \\
4.5 & .933 & .760 & 3.5 & .873 & .827 & 3.5 & .840 & .933 \\
5.5 & .927 & .793 & 4.5 & .867 & .867 & 4.5 & .827 & .933 \\
6.5 & .920 & .833 & 5.5 & .847 & .893 & 5.5 & .820 & .933 \\
7.5 & .920 & .853 & 6.5 & .827 & .900 & 6.5 & .813 & .933 \\
8.5 & .907 & .860 & 7.5 & .807 & .920 & 7.5 & .793 & .940 \\
9.5 & .907 & .867 & 8.5 & .787 & .920 & 9.0 & .767 & .953 \\
11.0 & .907 & 0.880 & 9.5 & .780 & .933 & 10.5 & .747 & .973 \\
13.0 & .907 & .893 & 10.5 & .767 & .947 & 11.5 & .740 & .980 \\
14.5 & .900 & .907 & 11.5 & .760 & .967 & 12.5 & .733 & .980 \\
\hline
\end{tabular}

$\mathrm{ROC}=$ receiver operating characteristic; $\mathrm{K}-\mathrm{VAPP}=$ the Korean version of the Voice Activity and Participation Profile, ALS= activity limitation score; PRS= participation restriction score.

본 연구에서는 K-VAPP가 타당도와 신뢰도를 갖춘 검사도구임 을 입증하는 데 주안점을 두었다. 그러나, K-VAPP를 활용하여 환 자군의 음성장애의 병인에 따라 서로 다른 주관적 음성장애 정도 가 보고될 가능성(Ricarte et al., 2013)까지 탐색하지는 못하였다. $\mathrm{VHI}$ 를 이용한 선행연구들에서는 다양한 결과들이 혼재되어 있 다. 가령, 신경학적 음성장애에서 더 심하게 보고된다는 연구도 있 는 반면, 기질-기능적(organo-functional) 음성장애에서 더 심하게 인식된다는 연구도 있다(Ricarte et al., 2013). VAPP는 활동과 참여 측면을 나누어 평가하므로, $\mathrm{VHI}$ 를 이용한 선행연구들과는 다른 양상이 나타날 수 있으며(Kleemola, Helminen, Rorarius, Sihvo, \& Isotalo, 2011b), 이를 중재 계획에 활용할 수 있는 가능성도 VHI보 다클수 있다(Ma \& Yiu, 2001).

아울러, 후속 연구에서는 이러한 비교에 있어 주관적 활동 제한 및 참여 제약의 정도에 영향을 미칠 수 있는 전문적(직업적) 음성 사용 여부가 고려되어야만 할 것이다(Zambon, Moreti, \& Behlau, 2014). 직업적 활동을 위해음성 사용에 의존하는 전문가들은 음성 장애가 발생할 경우 일반인에 비해 더욱 심한 음성 활동 제한과 참 여 제약을 느끼는 경향이 있기 때문이다(Dassie-Leite, Delazeri, Baldissarelli, Weber, \& de Lacerda Filho, 2014; Dragone, 2011) 또 한, 전문적 음성 사용자들 간에도 전문적 음성 사용의 수준이 다 를 수 있다는 점 또한 고려하여야만 한다(Kim, 2015). 선행연구들 을 살펴보면, 교사(Bassi et al., 2011; Cantor Cutiva \& Burdorf, 2014; 
Martinello, Lauris, \& Brasolotto, 2011; Zambon et al., 2014), 콜센 터 직원(Piwowarczyk, Oliveira, Lourenco, \& Behlau, 2012) 등의 직 업군에서 활동 제한 및 참여 제약이 더 크다. 따라서, 이에 따른 프로 파일 차이를 살펴보아야 할 것으로 여겨진다(Kleemola et al., 2011b).

자기보고식 심리측정적 검사도구를 통해 측정되는 주관적 음성 장애 정도와 전문가에 의한 청지각적 평가 결과, 그리고 객관적인 음향학적 평가 결과 사이의 상관관계 또한 연구되어 왔다(Bhuta, Patrick, \& Garnett, 2004; Kankare, Liu, Laukkanen, \& Geneid, 2013). 그 결과 대개 전문가에 의한 청지각적 평가 결과는 음향학적 평가 결과와 상관성이 높지만, 자기보고식 주관적 평가 결과는 그 렇지 않았다(Awan, Roy, \& Cohen, 2014; Kim \& Choi, 2009). 향후 $\mathrm{K}-\mathrm{VAPP}$ 로도 이를 확인해볼 필요가 있으며, 만약 심리측정적 평정 치가 전문가의 청지각 평가와 상관관계를 보인다면, 이를 이용하여 cepstral spectral index of dysphonia (CSID)와 같은 환자의 음성 중증도 수준을 대표하는 새로운 음성관련 지수가 도입될 수도 있 을 것이다(Awan, Roy, Zhang, \& Cohen, 2016).

$\mathrm{K}-\mathrm{VAPP}$ 는 활동 및 참여를 분리하여 살펴볼 수 있는 장점이 있으 나, KVHI에 비해 복잡한 점수 계산 방법으로 인하여 임상에서 사용 의 편이성이 다소 낮고 시각화하기 어려운 것이 사실이나, 엑셀시트 등의 활용을 통하여 극복할수 있을 것이다(https://goo.gl/PvQZmC). 또한, 임상에서의 유용성을 제고하기 위해 총점, ALS, PRS의 집단별 백분위수를 부록에 제시하였다(Appendixes 2-4). 본 연구는 여러 병 인집단 간에 연령, 성별, 전문적 음성 사용 여부 등을 일치시키지는 못하였다는 한계가 있으므로, 향후 이를 고려하여야 할 것으로 보인 다. 마지막으로, 수술적, 행동적 치료 전후의 프로파일 변화를 살펴 봄으로써 K-VAPP의 반응도(responsiveness) 또한 확보해야 하며, 이 러한 변화는 이전의 검사도구를 통해서는 확인할수 없었던 활동 및 참여 차원의 중재효과이므로 임상적 의의가 있을 것으로 여겨진다.

\section{REFERENCES}

Aaronson, N., Alonso, J., Burnam, A., Lohr, K. N., Patrick, D. L., Perrin, E., \&

Stein, R. E. (2002). Assessing health status and quality-of-life instruments: attributes and review criteria. Quality of Life Research, 11, 193-205.

Aronson, A. E., \& Bless, D. (2009). Clinical voice disorders. New York, NY: Thieme.

Awan, S. N., Roy, N., \& Cohen, S. M. (2014). Exploring the relationship between spectral and cepstral measures of voice and the Voice Handicap Index (VHI). Journal of Voice, 28, 430-439.

Awan, S. N., Roy, N., Zhang, D., \& Cohen, S. M. (2016). Validation of the ceps- tral spectral index of dysphonia (CSID) as a screening tool for voice disorders: development of clinical cutoff scores. Journal of Voice, 30, 130-144.

Bassi, I. B., Assunção, A. A., de Medeiros, A. M., de Menezes, L. N., Teixeira, L. C., \& Gama, A. C. C. (2011). Quality of life, self-perceived dysphonia, and diagnosed dysphonia through clinical tests in teachers. Journal of Voice, 25, 192-201.

Bhuta, T., Patrick, L., \& Garnett, J. D. (2004). Perceptual evaluation of voice quality and its correlation with acoustic measurements. Journal of Voice, 18, 299-304.

Cantor Cutiva, L. C., \& Burdorf, A. (2014). Factors associated with voice-related quality of life among teachers with voice complaints. Journal of Communication Disorders, 52, 134-142.

Dassie-Leite, A. P., Delazeri, S., Baldissarelli, B., Weber, J., \& de Lacerda Filho, L. (2014). Vocal self-assessment: relation with the type of instrument, gender, age, and profession in individuals without vocal complaints. CoDAS, 26, 531-534.

Deary, I. J., Wilson, J. A., Carding, P. N., \& MacKenzie, K. (2003). VoiSS: a patient-derived voice symptom scale. Journal of Psychosomatic Research, $54,483-489$.

Dragone, M. L. S. (2011). Voice activity and participation profile presenting coordinates for readjustment of preventive action of educators. Folia Phoniatrica et Logopaedica, 63, 49-54.

Faul, F., Erdfelder, E., Buchner, A., \& Lang, A. G. (2009). Statistical power analyses using $\mathrm{G}^{\star}$ Power 3.1: tests for correlation and regression analyses. Behavior Research Methods, 41, 1149-1160.

Fava, G., Paolillo, N. P., Oliveira, G., \& Behlau, M. (2015). Cross-cultural adaptation, validation, and cutoff point of the Italian version of the voice activity and participation profile: profilo di Attività e Partecipazione Vocale. Journal of Voice, 29, 130-e11.

Hirano, M. (1981). Clinical examination of voice. New York, NY: Springer.

Kankare, E., Liu, D., Laukkanen, A. M., \& Geneid, A. (2013). EGG and acoustic analyses of different voice samples: comparison between perceptual evaluation and voice activity and participation profile. Folia Phoniatrica et Logopaedica, 65, 98-104.

Kim, H. (2012). Neurogenic speech-language disorders. Seoul: Sigmapress.

Kim, J. (2015). Comparison of self-reporting voice evaluations between professional and non-professional voice users with voice disorders by severity and type. Phonetics and Speech Sciences, 7, 67-76.

Kim, J., \& Choi, H. S. (2009). Comparison of clinicians' perceptual evaluations and patients' subjective evaluations of voice disorders. Korean Jour- 
nal of Communication Disorders, 14, 223-235.

Kim, J., Lim, S. E., Park, S. Y., Choi, S., Choi, J. N., \& Choi, H. S. (2007). Validity and reliability of Korean-version of Voice Handicap Index and voicerelated quality of life. Speech Science, 14, 111-125.

Kleemola, L., Helminen, M., Rorarius, E., Isotalo, E., \& Sihvo, M. (2011a). Voice activity and participation profile in assessing the effects of voice disorders on quality of life: estimation of the validity, reliability and responsiveness of the Finnish version. Folia Phoniatrica et Logopaedica, 63, 113121.

Kleemola, L., Helminen, M., Rorarius, E., Sihvo, M., \& Isotalo, E. (2011b). Twelve-month clinical follow-up study of voice patients' recovery using the Voice Activity and Participation Profile (VAPP). Journal of Voice, 25, e245-e254.

Ma, E. M., \& Yiu, E. L. (2007). Scaling voice activity limitation and participation restriction in dysphonic individuals. Folia Phoniatrica et Logopaedica, 59, 74-82.

Ma, E. M., \& Yiu, E. M. (2011). Handbook of voice assessments. San Diego, CA: Plural Publishing.

Ma, E. P., \& Yiu, E. M. (2001). Voice activity and participation profileassessing the impact of voice disorders on daily activities. Journal of Speech, Language, and Hearing Research, 44, 511-524.

Martinello, J. G., Lauris, J. R. P., \& Brasolotto, A. G. (2011). Psychometric assessments of life quality and voice for teachers within the municipal system, in Bauru, SP, Brazil. Journal of Applied Oral Science, 19, 573-578.
Pires, M. D. E., Oliveira, G., \& Behlau, M. (2011). Aplicação do Protocolo de Participação e Atividades Vocais - PPAV em duas diferentes escalas de resposta [Voice Activity and Participation Profile-VAPP administered in two different scales of response]. Jornal da Sociedade Brasileira de Fonoaudiologia, 23, 297-300.

Piwowarczyk, T. C., Oliveira, G., Lourenço, L., \& Behlau, M. (2012). Vocal symptoms, voice activity, and participation profile and professional performance of call center operators. Journal of Voice, 26, 194-200.

Resnik, L., \& Plow, M. A. (2009). Measuring participation as defined by the international classification of functioning, disability and health: an evaluation of existing measures. Archives of Physical Medicine and Rehabilitation, 90, 856-866.

Ricarte, A., Oliveira, G., \& Behlau, M. (2013). Validation of the voice activity and participation profile protocol in Brazil. CoDAS, 25, 242-249.

Threats, T. T. (2008). Use of the ICF for clinical practice in speech-language pathology. International Journal of Speech-Language Pathology, 10, 50-60.

Yun, Y. S., Kim, H., Son, Y. I., \& Choi, H. S. (2008). Validation of the Korean Voice Handicap Index (K-VHI) and the clinical usefulness of Korean VHI10. Korean Journal of Communication Disorders, 13, 216-241.

Zambon, F., Moreti, F., \& Behlau, M. (2014). Coping strategies in teachers with vocal complaint. Journal of Voice, 28, 341-348.

Zraick, R. I., Risner, B. Y., Smith-Olinde, L., Gregg, B. A., Johnson, F. L., \& McWeeny, E. K. (2007). Patient versus partner perception of voice handicap. Journal of Voice, 21, 485-494. 
Seung Jin Lee, et al. • Korean Version of the Voice Activity and Participation Profile

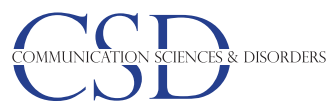

Appendix 1. Korean version of the Voice Activity and Participation Profile (K-VAPP)

\begin{tabular}{|c|c|c|c|c|c|c|c|c|c|c|c|c|c|c|c|c|c|}
\hline \multicolumn{2}{|c|}{ 전체점수 } & & & \multicolumn{2}{|c|}{ 영역별 점수 } & & & \multicolumn{5}{|c|}{ 프로파일 } & & & & & \\
\hline 점수 & 획득점수 & 만점 & \%ile & 영역 & 획득점수 & 만점 & \%ile & \multirow{6}{*}{$\begin{array}{l}\text { 표 } \\
\text { 준 } \\
\text { 점 } \\
\text { 수 }\end{array}$} & \multirow{6}{*}{$\begin{array}{r}2 \\
1 \\
0 \\
-1 \\
-2\end{array}$} & \multirow{3}{*}{$\begin{array}{l}0 \\
0 \\
0\end{array}$} & \multirow{3}{*}{$\begin{array}{l}0 \\
0 \\
0\end{array}$} & \multirow{2}{*}{$\begin{array}{l}0 \\
0\end{array}$} & \multirow{2}{*}{$\begin{array}{l}0 \\
0\end{array}$} & \multirow{2}{*}{$\begin{array}{l}0 \\
0\end{array}$} & \multirow{2}{*}{$\begin{array}{l}0 \\
0\end{array}$} & \multirow{2}{*}{$\begin{array}{l}0 \\
0\end{array}$} & \multirow{2}{*}{$\begin{array}{l}0 \\
0\end{array}$} \\
\hline \multirow{2}{*}{ 총점(TTL) } & & \multirow{2}{*}{280} & & I & & 10 & & & & & & & & & & & \\
\hline & & & & П & & 40 & & & & & & $\mathrm{O}$ & O & 0 & o & 0 & O \\
\hline 활동제한 & & 100 & & III & & 120 & & & & O & O & 0 & $\mathrm{O}$ & O & O & 0 & O \\
\hline 점수(ALS) & & & & & & & & & & 0 & 0 & 0 & 0 & 0 & 0 & 0 & 0 \\
\hline 참여제약 & & 100 & & IV & & 40 & & & & 0 & 0 & 0 & O & 0 & O & 0 & 0 \\
\hline 점수(PRS) & & 100 & & V & & 70 & & & & TTL & ALS & PRS & I & II & III & IV & V \\
\hline
\end{tabular}

각 질문을 읽고, 본인의 현재 목소리 상태가 어떠한지 0-10까지의 숫자 중 한 숫자를 골라서 동그라미 표시하세요. 0 에 가까울수록 목소리 문제가 전혀 없음을 뜻하고, 10 에 가까울수록 목소리 문제가 심각함을 뜻합니다.

표시 예: 전혀 아니다 $01234(5) 678910$ 항상 그렇다

\section{I. 목소리 문제의 심각한 정도에 대한 본인의 인식}

1. 현재 본인의 목소리 문제는 얼마나 심각합니까?

$$
\text { 정상이다 } \quad 012345678910 \text { 심각하다 }
$$

\section{II. 직업에 대한 영향}

A2. 현재의 목소리 문제 때문에 본인의 직장생활에 지장을 받습니까?

$$
\text { 전혀 아니다 } 012345678910 \text { 항상 그렇다 }
$$

P3. 지난 6개월 동안, 본인의 목소리 문제 때문에 직업을 바꿀 생각을 한 적이 있습니까? (실제로 바꾸려고 한 적이 있는지를 답하시면 됩니다) A4. 본인의 현재 목소리 문제 때문에 직장일에 대한 스트레스가 가중됩니까?

P5. 지난 6개월 동안, 본인의 목소리 문제가 앞으로의 경력에 관한 결정에 영향을 준 적이 있습니까? (실제로 영향을 준 적이 있는지를 답하시면 됩니다)

\section{III. 일상 의사소통에 대한 영향}

A6. 본인의 목소리 문제 때문에 다른 사람들이 방금 한 말을 다시 말해달라고 합니까?

P7. 지난 6개월 동안, 본인의 목소리 문제 때문에 다른 사람과 말하는 것을 피한 적이 있습니까? (실제로 피한 적이 있는지를 답하시면 됩니다)

A8. 본인의 목소리 문제 때문에 전화를 할 때 상대방이 본인의 말을 잘 이해하지 못합니까?

P9. 지난 6개월 동안, 본인의 목소리 문제 때문에 전화의 사용을 줄인 적이 있습니까? (실제로 줄인 적이 있는지를 답하시면 됩니다)

$\mathrm{A} 10$. 본인의 목소리 문제 때문에 조용한 환경에서 대화할 때 지장을 받습니까?

P11. 지난 6개월 동안, 본인의 목소리 문제 때문에 조용한 환경에서 대화하는 것을 피한 적이 있습니까? (실제로 피한 적이 있는지를 답하시면 됩니다)

A12. 본인의 목소리 문제 때문에 시끄러운 환경에서 대화할 때 지장을 받습니까?

P13. 지난 6개월 동안, 본인의 목소리 문제 때문에 시끄러운 환경에서 대화하는 것을 피한 적이 있습니까? (실제로 피한 적이 있는지를 답하시면 됩니다)

A14. 본인의 목소리 문제 때문에 여러 사람 앞에서 말할 때 내용 전달에 지장을 받습니까?

P15. 지난 6개월 동안, 본인의 목소리 문제 때문에 여러 사람 앞에서 말하는 것을 피한 적이 있습니까? (실제로 피한 적이 있는지를 답하시면 됩니다)

A16. 본인의 목소리 문제 때문에 본인의 말을 이해시키는 데 지장을 받습니까?

P17. 지난 6개월 동안, 본인의 목소리 문제 때문에 말하는 것을 피한 적이 있습니까? (실제로 피한 적이 있는지를 답하시면 됩니다)

\section{IV. 사회적 의사소통에 대한 영향}

A18. 본인의 목소리 문제 때문에 사회 활동에 지장을 받습니까?

P19. 지난 6개월 동안, 본인의 목소리 문제 때문에 사회 활동을 피한 적이 있습니까? (실제로 피한 적이 있는지를 답하시면 됩니다)

A20. 본인의 목소리 문제 때문에 본인의 가족, 친구, 동료들이 불쾌해합니까?

P21. 지난 6개월 동안, 본인의 목소리 문제 때문에 본인의 가족, 친구, 동료들과의 대화를 피한 적이 있습니까? (실제로 피한 적이 있는지를 답하시면 됩니다) 
Appendix 1. Continued

\section{$\mathrm{V}$. 본인의 감정에 대한 영향}

22. 본인의 목소리 문제 때문에 화가 납니까?

23. 본인의 목소리 문제 때문에 창피함을 느낍니까?

24. 본인의 목소리 문제 때문에 자존감이 낮아졌습니까?

25. 본인의 목소리 문제 때문에 걱정이 됩니까?

26. 본인의 목소리 문제 때문에 불만족스럽습니까?

27. 본인의 목소리 문제 때문에 본인의 성격이 영향을 받습니까?

28. 본인의 목소리 문제 때문에 자아상(자신에 대한 이미지나 생각)이 영향을 받습니까? 
Appendix 2. Percentile scores for the total score of the Korean version of the Voice Activity and Participation Profile

\begin{tabular}{|c|c|c|c|c|c|c|c|c|c|c|c|}
\hline \multirow{2}{*}{ Total score } & \multicolumn{2}{|c|}{ Group } & \multirow{2}{*}{ Total score } & \multicolumn{2}{|c|}{ Group } & \multirow{2}{*}{ Total score } & \multicolumn{2}{|c|}{ Group } & \multirow{2}{*}{ Total score } & \multicolumn{2}{|c|}{ Group } \\
\hline & Patient & Control & & Patient & Control & & Patient & Control & & Patient & Control \\
\hline 0 & $<1$ & $<1$ & & & & & & & & & \\
\hline 1 & 4 & 53 & 36 & 21 & 99 & 71 & 33 & $>99$ & 106 & 49 & $>99$ \\
\hline 2 & 4 & 62 & 37 & 22 & 99 & 72 & 33 & $>99$ & 117 & 49 & $>99$ \\
\hline 3 & 6 & 69 & 38 & 22 & 99 & 73 & 33 & $>99$ & 108 & 49 & $>99$ \\
\hline 4 & 7 & 75 & 39 & 22 & 99 & 74 & 34 & $>99$ & 109 & 49 & $>99$ \\
\hline 5 & 7 & 77 & 40 & 22 & 99 & 75 & 34 & $>99$ & 110 & 50 & $>99$ \\
\hline 6 & 8 & 80 & 41 & 22 & 99 & 76 & 34 & $>99$ & 111 & 50 & $>99$ \\
\hline 7 & 8 & 84 & 42 & 22 & $>99$ & 77 & 35 & $>99$ & 112 & 50 & $>99$ \\
\hline 8 & 8 & 86 & 43 & 23 & $>99$ & 78 & 35 & $>99$ & 113 & 51 & $>99$ \\
\hline 9 & 9 & 87 & 44 & 25 & $>99$ & 79 & 35 & $>99$ & 114 & 51 & $>99$ \\
\hline 10 & 9 & 88 & 45 & 25 & $>99$ & 80 & 35 & $>99$ & 115 & 51 & $>99$ \\
\hline 11 & 9 & 89 & 46 & 25 & $>99$ & 81 & 35 & $>99$ & 116 & 51 & $>99$ \\
\hline 12 & 10 & 89 & 47 & 26 & $>99$ & 82 & 35 & $>99$ & 117 & 52 & $>99$ \\
\hline 13 & 10 & 90 & 48 & 26 & $>99$ & 83 & 37 & $>99$ & 118 & 52 & $>99$ \\
\hline 14 & 10 & 90 & 49 & 26 & $>99$ & 84 & 37 & $>99$ & 119 & 53 & $>99$ \\
\hline 15 & 10 & 92 & 50 & 26 & $>99$ & 85 & 37 & $>99$ & 120 & 53 & $>99$ \\
\hline 16 & 11 & 92 & 51 & 26 & $>99$ & 86 & 38 & $>99$ & 121 & 53 & $>99$ \\
\hline 17 & 11 & 92 & 52 & 26 & $>99$ & 87 & 39 & $>99$ & 122 & 53 & $>99$ \\
\hline 18 & 12 & 93 & 53 & 27 & $>99$ & 88 & 40 & $>99$ & 123 & 53 & $>99$ \\
\hline 19 & 12 & 94 & 54 & 27 & $>99$ & 89 & 41 & $>99$ & 124 & 56 & $>99$ \\
\hline 20 & 14 & 94 & 55 & 27 & $>99$ & 90 & 42 & $>99$ & 125 & 56 & $>99$ \\
\hline 21 & 15 & 95 & 56 & 28 & $>99$ & 91 & 42 & $>99$ & 126 & 56 & $>99$ \\
\hline 22 & 16 & 95 & 57 & 28 & $>99$ & 92 & 42 & $>99$ & 127 & 57 & $>99$ \\
\hline 23 & 16 & 95 & 58 & 29 & $>99$ & 93 & 43 & $>99$ & 128 & 59 & $>99$ \\
\hline 24 & 17 & 95 & 59 & 29 & $>99$ & 94 & 44 & $>99$ & 129 & 59 & $>99$ \\
\hline 25 & 17 & 96 & 60 & 29 & $>99$ & 95 & 45 & $>99$ & 130 & 60 & $>99$ \\
\hline 26 & 17 & 97 & 61 & 30 & $>99$ & 96 & 45 & $>99$ & 131 & 61 & $>99$ \\
\hline 27 & 18 & 97 & 62 & 30 & $>99$ & 97 & 45 & $>99$ & 132 & 62 & $>99$ \\
\hline 28 & 19 & 97 & 63 & 30 & $>99$ & 98 & 46 & $>99$ & 133 & 62 & $>99$ \\
\hline 29 & 19 & 97 & 64 & 30 & $>99$ & 99 & 46 & $>99$ & 134 & 63 & $>99$ \\
\hline 30 & 19 & 97 & 65 & 31 & $>99$ & 100 & 46 & $>99$ & 135 & 63 & $>99$ \\
\hline 31 & 20 & 97 & 66 & 31 & $>99$ & 101 & 46 & $>99$ & 136 & 63 & $>99$ \\
\hline 32 & 20 & 97 & 67 & 31 & $>99$ & 102 & 47 & $>99$ & 137 & 63 & $>99$ \\
\hline 33 & 20 & 97 & 68 & 32 & $>99$ & 103 & 47 & $>99$ & 138 & 64 & $>99$ \\
\hline 34 & 20 & 98 & 69 & 32 & $>99$ & 104 & 48 & $>99$ & 139 & 64 & $>99$ \\
\hline 35 & 21 & 98 & 70 & 33 & $>99$ & 105 & 48 & $>99$ & 140 & 64 & $>99$ \\
\hline 141 & 65 & $>99$ & 176 & 78 & $>99$ & 211 & 87 & $>99$ & 246 & 93 & $>99$ \\
\hline 142 & 65 & $>99$ & 177 & 78 & $>99$ & 212 & 87 & $>99$ & 247 & 94 & $>99$ \\
\hline 143 & 65 & $>99$ & 178 & 78 & $>99$ & 213 & 87 & $>99$ & 248 & 95 & $>99$ \\
\hline 144 & 66 & $>99$ & 179 & 78 & $>99$ & 214 & 87 & $>99$ & 249 & 95 & $>99$ \\
\hline 145 & 68 & $>99$ & 180 & 78 & $>99$ & 215 & 88 & $>99$ & 250 & 95 & $>99$ \\
\hline 146 & 68 & $>99$ & 181 & 78 & $>99$ & 216 & 88 & $>99$ & 251 & 95 & $>99$ \\
\hline 147 & 68 & $>99$ & 182 & 78 & $>99$ & 217 & 89 & $>99$ & 252 & 95 & $>99$ \\
\hline 148 & 68 & $>99$ & 183 & 78 & $>99$ & 218 & 89 & $>99$ & 253 & 96 & $>99$ \\
\hline 149 & 68 & $>99$ & 184 & 79 & $>99$ & 219 & 89 & $>99$ & 254 & 96 & $>99$ \\
\hline 150 & 69 & $>99$ & 185 & 79 & $>99$ & 220 & 89 & $>99$ & 255 & 96 & $>99$ \\
\hline
\end{tabular}


Appendix 2. Continued

\begin{tabular}{|c|c|c|c|c|c|c|c|c|c|c|c|}
\hline \multirow{2}{*}{ Total score } & \multicolumn{2}{|c|}{ Group } & \multirow{2}{*}{ Total score } & \multicolumn{2}{|c|}{ Group } & \multirow{2}{*}{ Total score } & \multicolumn{2}{|c|}{ Group } & \multirow{2}{*}{ Total score } & \multicolumn{2}{|c|}{ Group } \\
\hline & Patient & Control & & Patient & Control & & Patient & Control & & Patient & Control \\
\hline 151 & 69 & $>99$ & 186 & 79 & $>99$ & 221 & 89 & $>99$ & 256 & 96 & $>99$ \\
\hline 152 & 69 & $>99$ & 187 & 81 & $>99$ & 222 & 89 & $>99$ & 257 & 97 & $>99$ \\
\hline 153 & 70 & $>99$ & 188 & 81 & $>99$ & 223 & 89 & $>99$ & 258 & 97 & $>99$ \\
\hline 154 & 70 & $>99$ & 189 & 81 & $>99$ & 224 & 89 & $>99$ & 259 & 97 & $>99$ \\
\hline 155 & 70 & $>99$ & 190 & 81 & $>99$ & 225 & 89 & $>99$ & 260 & 97 & $>99$ \\
\hline 156 & 71 & $>99$ & 191 & 82 & $>99$ & 226 & 89 & $>99$ & 261 & 97 & $>99$ \\
\hline 157 & 71 & $>99$ & 192 & 82 & $>99$ & 227 & 90 & $>99$ & 262 & 97 & $>99$ \\
\hline 158 & 72 & $>99$ & 193 & 83 & $>99$ & 228 & 90 & $>99$ & 263 & 98 & $>99$ \\
\hline 159 & 73 & $>99$ & 194 & 84 & $>99$ & 229 & 90 & $>99$ & 264 & 98 & $>99$ \\
\hline 160 & 73 & $>99$ & 195 & 84 & $>99$ & 230 & 90 & $>99$ & 265 & 98 & $>99$ \\
\hline 161 & 73 & $>99$ & 196 & 84 & $>99$ & 231 & 90 & $>99$ & 266 & 98 & $>99$ \\
\hline 162 & 73 & $>99$ & 197 & 85 & $>99$ & 232 & 90 & $>99$ & 267 & 98 & $>99$ \\
\hline 163 & 74 & $>99$ & 198 & 85 & $>99$ & 233 & 90 & $>99$ & 268 & 98 & $>99$ \\
\hline 164 & 74 & $>99$ & 199 & 86 & $>99$ & 234 & 91 & $>99$ & 269 & 98 & $>99$ \\
\hline 165 & 74 & $>99$ & 200 & 86 & $>99$ & 235 & 91 & $>99$ & 270 & 99 & $>99$ \\
\hline 166 & 75 & $>99$ & 201 & 86 & $>99$ & 236 & 91 & $>99$ & 271 & 99 & $>99$ \\
\hline 167 & 75 & $>99$ & 202 & 86 & $>99$ & 237 & 91 & $>99$ & 272 & 99 & $>99$ \\
\hline 168 & 75 & $>99$ & 203 & 86 & $>99$ & 238 & 91 & $>99$ & 273 & 99 & $>99$ \\
\hline 169 & 75 & $>99$ & 204 & 86 & $>99$ & 239 & 91 & $>99$ & 274 & 99 & $>99$ \\
\hline 170 & 76 & $>99$ & 205 & 86 & $>99$ & 240 & 91 & $>99$ & 275 & 99 & $>99$ \\
\hline 171 & 76 & $>99$ & 206 & 87 & $>99$ & 241 & 91 & $>99$ & 276 & 99 & $>99$ \\
\hline 172 & 76 & $>99$ & 207 & 87 & $>99$ & 242 & 91 & $>99$ & 277 & $>99$ & $>99$ \\
\hline 173 & 77 & $>99$ & 208 & 87 & $>99$ & 243 & 92 & $>99$ & 278 & $>99$ & $>99$ \\
\hline 174 & 78 & $>99$ & 209 & 87 & $>99$ & 244 & 92 & $>99$ & 279 & $>99$ & $>99$ \\
\hline 175 & 78 & $>99$ & 210 & 87 & $>99$ & 245 & 93 & $>99$ & 280 & $>99$ & $>99$ \\
\hline
\end{tabular}


Seung Jin Lee, et al. • Korean Version of the Voice Activity and Participation Profile

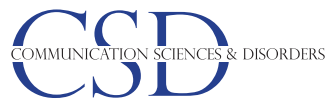

Appendix 3. Percentile scores for the activity limitation score (ALS) of the Korean version of the Voice Activity and Participation Profile

\begin{tabular}{|c|c|c|c|c|c|c|c|c|}
\hline \multirow{2}{*}{ ALS } & \multicolumn{2}{|c|}{ Group } & \multirow{2}{*}{ ALS } & \multicolumn{2}{|c|}{ Group } & \multirow{2}{*}{ ALS } & \multicolumn{2}{|c|}{ Group } \\
\hline & Patient & Control & & Patient & Control & & Patient & Control \\
\hline 0 & $<1$ & $<1$ & & & & & & \\
\hline 1 & 7 & 63 & 36 & 54 & $>99$ & 71 & 85 & $>99$ \\
\hline 2 & 9 & 70 & 37 & 55 & $>99$ & 72 & 86 & $>99$ \\
\hline 3 & 12 & 79 & 38 & 55 & $>99$ & 73 & 87 & $>99$ \\
\hline 4 & 13 & 84 & 39 & 57 & $>99$ & 74 & 87 & $>99$ \\
\hline 5 & 14 & 88 & 40 & 59 & $>99$ & 75 & 88 & $>99$ \\
\hline 6 & 16 & 90 & 41 & 60 & $>99$ & 76 & 88 & $>99$ \\
\hline 7 & 18 & 91 & 42 & 60 & $>99$ & 77 & 89 & $>99$ \\
\hline 8 & 20 & 93 & 43 & 60 & $>99$ & 78 & 89 & $>99$ \\
\hline 9 & 22 & 93 & 44 & 62 & $>99$ & 79 & 90 & $>99$ \\
\hline 10 & 23 & 94 & 45 & 64 & $>99$ & 80 & 91 & $>99$ \\
\hline 11 & 24 & 96 & 46 & 64 & $>99$ & 81 & 92 & $>99$ \\
\hline 12 & 25 & 98 & 47 & 66 & $>99$ & 82 & 92 & $>99$ \\
\hline 13 & 25 & 98 & 48 & 66 & $>99$ & 83 & 92 & $>99$ \\
\hline 14 & 26 & $>99$ & 49 & 67 & $>99$ & 84 & 93 & $>99$ \\
\hline 15 & 26 & $>99$ & 50 & 68 & $>99$ & 85 & 95 & $>99$ \\
\hline 16 & 27 & $>99$ & 51 & 69 & $>99$ & 86 & 95 & $>99$ \\
\hline 17 & 30 & $>99$ & 52 & 69 & $>99$ & 87 & 95 & $>99$ \\
\hline 18 & 31 & $>99$ & 53 & 70 & $>99$ & 88 & 95 & $>99$ \\
\hline 19 & 32 & $>99$ & 54 & 72 & $>99$ & 89 & 96 & $>99$ \\
\hline 20 & 34 & $>99$ & 55 & 73 & $>99$ & 90 & 96 & $>99$ \\
\hline 21 & 34 & $>99$ & 56 & 73 & $>99$ & 91 & 97 & $>99$ \\
\hline 22 & 35 & $>99$ & 57 & 74 & $>99$ & 92 & 97 & $>99$ \\
\hline 23 & 35 & $>99$ & 58 & 76 & $>99$ & 93 & 98 & $>99$ \\
\hline 24 & 36 & $>99$ & 59 & 76 & $>99$ & 94 & 98 & $>99$ \\
\hline 25 & 37 & $>99$ & 60 & 78 & $>99$ & 95 & 98 & $>99$ \\
\hline 26 & 37 & $>99$ & 61 & 78 & $>99$ & 96 & 99 & $>99$ \\
\hline 27 & 37 & $>99$ & 62 & 79 & $>99$ & 97 & 99 & $>99$ \\
\hline 28 & 38 & $>99$ & 63 & 80 & $>99$ & 98 & 99 & $>99$ \\
\hline 29 & 43 & $>99$ & 64 & 81 & $>99$ & 99 & 99 & $>99$ \\
\hline 30 & 43 & $>99$ & 65 & 82 & $>99$ & 100 & 99 & $>99$ \\
\hline 31 & 45 & $>99$ & 66 & 82 & $>99$ & & & \\
\hline 32 & 47 & $>99$ & 67 & 82 & $>99$ & & & \\
\hline 33 & 49 & $>99$ & 68 & 83 & $>99$ & & & \\
\hline 34 & 50 & $>99$ & 69 & 84 & $>99$ & & & \\
\hline 35 & 52 & $>99$ & 70 & 84 & $>99$ & & & \\
\hline
\end{tabular}


Appendix 4. Percentile scores for the participation restriction score (PRS) of the Korean version of the Voice Activity and Participation Profile

\begin{tabular}{|c|c|c|c|c|c|c|c|c|}
\hline \multirow{2}{*}{ PRS } & \multicolumn{2}{|c|}{ Group } & \multirow{2}{*}{ PRS } & \multicolumn{2}{|c|}{ Group } & \multirow{2}{*}{ PRS } & \multicolumn{2}{|c|}{ Group } \\
\hline & Patient & Control & & Patient & Control & & Patient & Control \\
\hline 0 & $<1$ & $<1$ & & & & & & \\
\hline 1 & 10 & 82 & 36 & 51 & $>99$ & 71 & 86 & $>99$ \\
\hline 2 & 13 & 88 & 37 & 53 & $>99$ & 72 & 86 & $>99$ \\
\hline 3 & 14 & 92 & 38 & 55 & $>99$ & 73 & 86 & $>99$ \\
\hline 4 & 17 & 94 & 39 & 57 & $>99$ & 74 & 87 & $>99$ \\
\hline 5 & 18 & 94 & 40 & 58 & $>99$ & 75 & 87 & $>99$ \\
\hline 6 & 19 & 94 & 41 & 58 & $>99$ & 76 & 87 & $>99$ \\
\hline 7 & 19 & 94 & 42 & 61 & $>99$ & 77 & 88 & $>99$ \\
\hline 8 & 21 & 95 & 43 & 62 & $>99$ & 78 & 88 & $>99$ \\
\hline 9 & 24 & 96 & 44 & 62 & $>99$ & 79 & 89 & $>99$ \\
\hline 10 & 24 & 96 & 45 & 63 & $>99$ & 80 & 89 & $>99$ \\
\hline 11 & 26 & 98 & 46 & 63 & $>99$ & 81 & 89 & $>99$ \\
\hline 12 & 27 & 99 & 47 & 65 & $>99$ & 82 & 89 & $>99$ \\
\hline 13 & 27 & 99 & 48 & 66 & $>99$ & 83 & 89 & $>99$ \\
\hline 14 & 28 & $>99$ & 49 & 67 & $>99$ & 84 & 89 & $>99$ \\
\hline 15 & 29 & $>99$ & 50 & 69 & $>99$ & 85 & 90 & $>99$ \\
\hline 16 & 29 & $>99$ & 51 & 70 & $>99$ & 86 & 90 & $>99$ \\
\hline 17 & 31 & $>99$ & 52 & 72 & $>99$ & 87 & 91 & $>99$ \\
\hline 18 & 33 & $>99$ & 53 & 72 & $>99$ & 88 & 91 & $>99$ \\
\hline 19 & 36 & $>99$ & 54 & 75 & $>99$ & 89 & 92 & $>99$ \\
\hline 20 & 37 & $>99$ & 55 & 75 & $>99$ & 90 & 92 & $>99$ \\
\hline 21 & 38 & $>99$ & 56 & 76 & $>99$ & 91 & 94 & $>99$ \\
\hline 22 & 39 & $>99$ & 57 & 77 & $>99$ & 92 & 96 & $>99$ \\
\hline 23 & 39 & $>99$ & 58 & 77 & $>99$ & 93 & 96 & $>99$ \\
\hline 24 & 40 & $>99$ & 59 & 78 & $>99$ & 94 & 97 & $>99$ \\
\hline 25 & 41 & $>99$ & 60 & 78 & $>99$ & 95 & 97 & $>99$ \\
\hline 26 & 42 & $>99$ & 61 & 79 & $>99$ & 96 & 98 & $>99$ \\
\hline 27 & 42 & $>99$ & 62 & 79 & $>99$ & 97 & 98 & $>99$ \\
\hline 28 & 43 & $>99$ & 63 & 81 & $>99$ & 98 & 99 & $>99$ \\
\hline 29 & 45 & $>99$ & 64 & 81 & $>99$ & 99 & 99 & $>99$ \\
\hline 30 & 46 & $>99$ & 65 & 82 & $>99$ & 100 & $>99$ & $>99$ \\
\hline 31 & 47 & $>99$ & 66 & 84 & $>99$ & & & \\
\hline 32 & 48 & $>99$ & 67 & 84 & $>99$ & & & \\
\hline 33 & 49 & $>99$ & 68 & 85 & $>99$ & & & \\
\hline 34 & 49 & $>99$ & 69 & 85 & $>99$ & & & \\
\hline 35 & 50 & $>99$ & 70 & 86 & $>99$ & & & \\
\hline
\end{tabular}




\section{국문초록}

\section{음성 활동 및 참여 프로파일-한국판(K-VAPP): 타당성 검증 연구}

이승진 ${ }^{1,2} \cdot$ 최홍식 ${ }^{2,3} \cdot$ 김향희 ${ }^{1,4} \cdot$ 변형권 2,3 - 임성은 5 양민교 2,6

${ }^{1}$ 연세대학교 대학원 언어병리학협동과정, ${ }^{2}$ 강남세브란스병원 이비인후과 후두음성언어의학연구소, ${ }^{3}$ 연세대학교 의과대학 이비인후과학교실, ${ }^{4}$ 연세대학교 의과대학

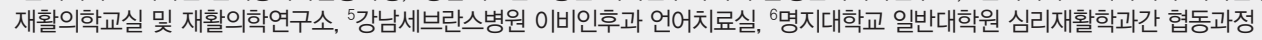

배경 및 목적: 우리나라 음성 클리닉의 임상 현장에서는 환자 보고에 의한 심리측정적 평가도구가 부족하며, 활동 및 참여 측면까지 고 려한 검사도구는 전무하다. 이에, 본 연구에서는 ‘음성 활동 및 참여 프로파일-한국판(K-VAPP)의 타당성을 검증하고자 하였다. 방법: 개념적 및 언어적 등가성을 위해 권고되는 절차에 따라 ‘음성 활동 및 참여 프로파일’을 한국어로 번역하여 300명의 대상자(음성장애 환자 150 명 및 대조군 150 명)에게 시행하였다. 타당도 검증을 위해 5 년 이상 경력의 언어재활사 4 인의 검증과 예비시행, 집단 간 점수 비 교, 문항변별도 산출과 음성장애지수와의 상관관계 검증을 실시하였다. 신뢰도 검증을 위해 내적 일치도, 검사-재검사 신뢰도를 산출 하고, 절단점을 확인하였다. 결과: 환자군의 총점, 활동 제한 점수, 참여 제약 점수, 하위영역별 점수가 대조군에 비해 높았으며, 충분한 수준의 신뢰도 및 타당도를 갖춘 검사도구임이 확인되었다. 총점, 활동 제한 점수, 참여 제약 점수의 절단점은 각각 14.5점, 4.5점, 1.5 점 이었다. 논의 및 결론: K-VAPP가 우리나라 음성장애 임상현장에서 충분한 타당도와 신뢰도를 갖춘 도구로 활용될 수 있음을 확인하 였다.

핵심어: 음성 활동 및 참여 프로파일-한국판, 타당성 검증, $\mathrm{K}-\mathrm{VAPP}$, 심리측정적 평가, 음성장애

본 연구는 2016년 한국언어청각임상학회 학술대회에서 일부 발표되었으며, 우수논문상을 수상하였음.

\section{참고문헌}

김재옥(2015). 음성장애가 있는 직업적 음성사용자와 비직업적 음성사용자의 음성장애 중증도와 유형에 따른 자기보고식 음성평가 차이. 말소리와 음성과학, 7, 67-76

김재옥, 임성은, 박선영, 최성희, 최재남, 최홍식(2007). 한국어판 음성장애지수와 음성관련 삶의 질의 타당도 및 신뢰도 연구. 음성과학, 14, 111-125. 김재옥, 최홍식(2009). 평가자의 청지각적 음성평가와 대상자의 주관적 음성평가 비교. 언어청각장애연구, 14, 223-235.

김향희(2012). 신경언어장애. 서울: 시그마프레스.

윤영선, 김향희, 손영익, 최홍식(2008). 한국어판 음성장애지수(Voice Handicap Index, VHI)의 타당도 및 VHI-10의 임상적 유용성. 언어청각장애연

구, 13, 216-241. 